\title{
Order-Preserving and Order-Reversing Mappings between Consumption Bundles and Utilities
}

\author{
Chunhua Jin \\ School of Economics and Management, Beijing Information Science and Technology University, Beijing 100 192, China \\ Correspondence should be addressed to Chunhua Jin; chhking@bistu.edu.cn
}

Received 21 March 2021; Revised 25 October 2021; Accepted 14 November 2021; Published 14 December 2021

Academic Editor: Eulalia Mart nez

Copyright (c 2021 Chunhua Jin. This is an open access article distributed under the Creative Commons Attribution License, which permits unrestricted use, distribution, and reproduction in any medium, provided the original work is properly cited.

\begin{abstract}
Economics and management believe that income and price play decisive roles in consumer demand for commodities. However, there is no analysis of the order-preserving or order-reversing mapping between consumer demand and utility when income and price are not constrained. Customer utility is always determined by the amount of commodities in real life. This research analyzes the mapping relationship between the amount of commodities and utility. The set which consists of consumption bundles with a binary relation is a poset. The set of utility values with the binary relation is a chain. Furthermore, the relationship between consumption bundles and utilities is illustrated by figures. If the increasing directions of utility and the amount of commodities are consistent, the utility function is order-preserving. If they are opposite, the utility function is order-reversing. Finally, examples are included to illustrate the mapping relationship between consumption bundles and utilities.
\end{abstract}

\section{Introduction}

Customer preference is an important market information which is a useful guideline during decision-making. Preference is often reflected by customer utility. Utility refers to the psychological satisfaction when customers purchase commodities [1]. Utility can be divided into cardinal utility and ordinal utility. Because the utility cannot be well quantified, the study of utility in economics is mainly the analysis of ordinal utility. Theories and applications of preference and utility have been hot questions. For example, Kruse [2] proposed a separation of the von Neumann-Morgenstern utility function into two parts. One part measures the preferences under certainty; the other part measures the pure risk preferences. Revealed preference theory is a domain within economics that studies rationalizability of behavior by utility functions [3]. In economic evaluation of health programmes, measuring health-related quality of life is an important aspect, and the development of utility-based (preference-based) measures is advanced by the discipline of health economics. Different preference measures are applied for valuing health states to produce a weighted health state index [4]. Estimating preferences for states of health has been an active area of research in recent years. Unlike psychophysical approaches, which discriminate levels of health status, preference-based approaches incorporate values or utilities for health outcomes and can be used in cost-effectiveness analyses to aid resource allocation decisions [5]. Revicki and Kaplan [6] summarized selected evidence pertaining to the relationship between psychometric health status measures and utility/preference measures of health outcome. Furthermore, preference and utility have been introduced in more literatures in several fields, such as [7-16].

Customer demand for the commodities is closely related to their purchase probability, which depends on their utility [17]. Customer utility theory, which is generated based on combination of consumer behavior and modern utility theory, is the main theory in the field of marketing management. When customers purchase commodities, the use value of commodities is obtained, and a kind of consumption desire is satisfied. In reality, besides being closely related to the customer utility value of commodities brand, the quantity of commodities also determines the customer utility after using commodities $[18,19]$. This paper analyzes the relationship between the amount of commodities, 
customer preference, and utility; The purpose is to reflect customer preference according to the amount of commodities. The objects of consumer choice are consumption bundles; All the consumption bundles constitute a set; the set with a binary relation is a poset. Consumer preference is complete, reflexive, and transitive. Utility reflects the degree of consumer likes consumption bundle. Any two utility values can be compared. The set which consists of all the utility values is a chain. If the amount of commodities in the consumption bundle is greater, the utility value of the customer is greater, then, the utility function is order-preserving. If the amount of commodities is smaller, the utility value of the customer is greater, then the utility function is order-reversing. In this case, if the relationship between utility and the amount of commodities is known, customer preferences can be directly reflected by the amount of commodities, and it is more beneficial to make decisions for enterprises.

The remainder of the paper is as follows: in Section 2, consumer preference and chain are introduced. In Section 3, mapping between consumption bundle and utility is analysed. Section 4 presents classic examples to illustrate the mapping relation. Section 5 concludes this paper.

\section{Preliminaries}

2.1. Consumer Preference. Preference refers to how much consumers like the commodities. The objects of consumer choice are called consumption bundles, denoted by $X$. There are $M$ commodities to consume, $N$ objects of consumer choice, $X=\left\{X^{1}, X^{2}, \ldots, X^{N}\right\}$, and $X^{i}=\left\{x_{1}^{i}, x_{2}^{i}, \ldots, x_{M}^{i}\right\}$, $i=1,2, \ldots, N$.

Preference relation $\geqslant,>$, and $\sim$ are binary relations defined in consumption bundles $X . X^{i}, X^{j} \in X$; if the consumer prefers or is indifferent between the two bundles $X^{i}$ and $X^{j}$, we say that the consumer weakly prefers $X^{i}$ to $X^{j}$, and write $X^{i} \geqslant X^{j}$. If the consumer strictly prefers bundle $X^{i}$ to $X^{j}$, preference relation is denoted by $>$, and we write $X^{i}>X^{j}$. If the consumer is indifferent between two bundles $X^{i}$ and $X^{j}$, preference relation is denoted by the symbol $\sim$, and $X^{i} \sim X^{j}$.

In order to illustrate how the consumer preference relations work, three axioms are given as follows:

(1) Complete: From any consumption bundles $X^{i}$, $X^{j} \in X$, we assume that $X^{i} \geqslant X^{j}$ or $X^{j} \geqslant X^{i}$ or $X^{i} \sim X^{j}$

(2) Reflexive: any bundle $X^{i}$ is at least as good as itself, $X^{i} \sim X^{i}$

(3) Transitive: if $X^{i} \geqslant X^{j}$ and $X^{j} \geqslant X^{k}$, then we assume that $X^{i} \geqslant X^{k}$

2.2. Chain. Let $P$ be a set. An order on $P$ is a binary relation $R$ on $P$ such that, for all $x$ and $y$,
(i) $x R x$
(ii) xRy and yRx imply $x=y$
(iii) $x R y$ and $y R z$ imply $x \mathrm{Rz}$

Conditions (i), (ii), and (iii) are referred as reflexivity, antisymmetry, and transitivity. The set $P$, equipped with an order relation $R$ is said to be a poset, and is denoted by $(P, R)$. If any two elements of $P$ are comparable, then $P$ is a chain [20].

Definition 1. Let $\left(P_{1}, \geq\right)$ and $\left(P_{2}, \geq\right)$ be posets; $\geq$ is a binary relation. A map $\psi: P_{1} \longrightarrow P_{2}$ is said to be

(i) Order-preserving if $x \geq y$ in $P_{1}$ implies $\psi(x) \geq \psi(y)$ in $P_{2}$

(ii) Order-reversing if $x \geq y$ in $P_{1}$ implies $\psi(y) \leq \psi(x)$ in $P_{2}$

\section{Mapping between Consumption Bundle and Utility}

3.1. Analysis of Mapping Relations. Let the binary relations $\geq$ and $\leq$ be symbols of quantity. $X=\left\{X^{1}, X^{2}, \ldots, X^{N}\right\}$ is a quantity set; some elements may be incomparable. Taking an arbitrary element $X^{i}$ from $X$, we have $X^{i} \leq X^{i}$, that is to say, $x_{1}^{i} \leq x_{1}^{i}, x_{2}^{i} \leq x_{2}^{i}, \cdots, x_{M}^{i} \leq x_{M}^{i}$; then, $X$ with the binary relation $\leq$ is reflexive. Arbitrary elements $X^{i}, X^{j} \in X$; if $X^{i} \leq X^{j}$ and $X^{j} \leq X^{i}$, then $X^{i}=X^{j}, X$ with the binary relation $\leq$ is antisymmetric. For arbitrary elements $X^{i}, X^{j}$, $X^{k} \in\left\{X^{1}, X^{2}, \ldots, X^{N}\right\}$, if $X^{i} \leq X^{j}$ and $X^{j} \leq X^{k}$, then $X^{i} \leq X^{k}$, and then, $X$ with $\leq$ is transitive. Thus, $\left\{X^{1}, X^{2}, \ldots, X^{N}\right\}$ with the binary relation $\leq$ is a poset.

Taking an arbitrary consumption bundles $X^{i}$ from $X$, we know that $X^{i}$ is at least as good as itself, i.e., $X^{i} \sim X^{i}$, that is to say, $x^{i} \geqslant x^{i}$; then, $X$ with preference relation $\geqslant$ is reflexive. From any consumption bundle $X^{i}, X^{j} \in X$, if $X^{i} \geqslant X^{j}$ and $X^{j} \geqslant X^{i}$, then the consumer is indifferent between the two consumption bundles, and $X^{i} \sim X^{j}, X$ with preference relation $\geqslant$ is antisymmetric. Furthermore, consumption bundles are complete and transitive from consumer preference axioms; we know $X$ with preference relation $\geqslant$ is a chain.

A utility function is a way of assigning a number to every possible consumption bundle such that more-preferred bundles get assigned larger numbers than less-preferred bundles. That is, a bundle $X^{i}$ is preferred to a bundle $X^{j}$ if and only if the utility of $X^{i}$ is larger than the utility of $X^{j}$ [21]. In the case, a real function $u: R^{M} \longrightarrow R$ is called a utility function if the real function satisfies

(1) $u\left(X^{i}\right) \geq u\left(X^{j}\right)$ if and only if $X^{i} \geqslant X^{j}$

(2) $u\left(X^{i}\right)=u\left(X^{j}\right)$ if and only if $X^{i} \sim X^{j}$

If the utility function value of $u$ is equal to a constant $c$, the preference of consumption bundles $\{x \mid u(x)=c\}$ is indifferent, and the graph is an indifference curve. The range of utility function on $X$ is $u(X)=\left\{u\left(X^{1}\right), u\left(X^{2}\right), \ldots, u\left(X^{N}\right)\right\}$. Taking any utility function values $u\left(X^{i}\right), u\left(X^{j}\right)$, and $u\left(X^{k}\right)$, we have

(i) $u\left(X^{i}\right) \geq u\left(X^{i}\right)$

(ii) If $u\left(X^{i}\right) \geq u\left(X^{j}\right)$ and $u\left(X^{j}\right) \geq u\left(X^{i}\right)$, then $u\left(X^{i}\right)=u\left(X^{j}\right)$

(iii) If $u\left(X^{i}\right) \geq u\left(X^{j}\right)$ and $u\left(X^{j}\right) \geq u\left(X^{k}\right)$, then $u\left(X^{i}\right) \geq u\left(X^{k}\right)$ 
The set $u(X)$ with order relation $\geq$ is reflexive, antisymmetric, and transitive; then, $(u(X), \geq)$ is a poset. Moreover, consumption bundles are complete; then, utility function values are also complete, $u(X)$, with order relation $\geq$ is a chain.

For arbitrary consumer choices $X^{i}$ and $X^{j}$, if $X^{i} \geq X^{j}$ and $u\left(X^{i}\right) \geq u\left(X^{j}\right)$, then the utility function $u$ is order-preserving. If $X^{i} \geq X^{j}$ and $u\left(X^{i}\right) \leq u\left(X^{j}\right)$, then the utility function is order-reversing. For the convenience of reading, the notations and their meanings are summarized in Table 1.

3.2. The Application of Mapping Relations. The formation of consumers' preferences is mostly determined by many factors, such as consumers' social environment, customs, family background, and fashion transformation. The strong tendency of consumers' purchase behavior can be caused by consumer preference. If consumers' preferences and intentions are explored and predicted, the market demand of products will inevitably be improved. Therefore, it is very necessary to study order-preserving and order-reversing mappings between consumption bundles and utilities. In view of the choice behavior of different passengers, a theoretical basis for the optimal design of train operation can be provided based on the mapping relationship between ticket price and passengers' age, travel distance, and monthly income. If the logistics cost of commodities is reduced, the selling price of goods will be reduced. Consumers can buy more homogeneous commodities without changing their consumption expenditures, so as to make consumers more effective and drive consumer behavior. The circulation and sharing of data resources is the key to big data application, and the premise of data circulation is reasonable fixing a price. With the mapping relationship between the cost of data production and user utility, the consumption behavior of buyers is analysed, and then, prices of big data products can be fixed.

\section{Illustrated Examples}

For the sake of focusing on the tradeoff between one commodity and everything else, two commodities are used in this section to analyse the mapping of consumer choice and utility. $x_{1}$ denotes the amount of one commodity. Another commodity is "all other commodities," and its amount is denoted by $x_{2}$. In this way, we can consider consumption choices involving many commodities and still use two-dimensional diagrams. The complete consumption bundle is, therefore, denoted by $\left(x_{1}, x_{2}\right)$. As noted above, we will occasionally abbreviate this consumption bundle by $x$.

4.1. Perfect Substitutes. Two commodities are perfect substitutes if the consumer is willing to substitute one commodity for the other at a constant rate. Utility function of perfect substitute is

$$
u\left(x_{1}, x_{2}\right)=k_{1}^{1} x_{1}+k_{1}^{2} x_{2},
$$

where $0<k_{1}^{1}<+\infty$ and $0<k_{1}^{2}<+\infty$. The important fact about perfect substitutes is that the indifference curves have
TABle 1: Japanese companies.

\begin{tabular}{lc}
\hline Notation & Meaning \\
\hline$\geqslant$ & Weakly prefer \\
$>$ & Strictly prefer \\
$\sim$ & Indifferent \\
$R$ & Binary relation \\
$\leq$ & Less than or equal to \\
$=$ & Equal to \\
$\geq$ & Greater than or equal to \\
\hline
\end{tabular}

a constant slope. Suppose $u\left(x_{1}, x_{2}\right)=u_{1}$; the preference of consumption bundles $\left\{\left(x_{1}, x_{2}\right) \mid k_{1}^{1} x_{1}+k_{1}^{2} x_{2}=u_{1}\right\}$ is indifferent, and corresponding function of indifference curve is as follows:

$$
x_{2}=\frac{1}{k_{1}^{2}} u_{1}-\frac{k_{1}^{1}}{k_{1}^{2}} x_{1}, x_{1} \in\left[0, \frac{1}{k_{1}^{1}} u_{1}\right] .
$$

The graph of the indifference curve is depicted in Figure 1. The amount of one commodity can be equal to zero; the commodity is completely substituted by another commodity.

For any consumption bundles $\left(x_{1}^{1}, x_{2}^{1}\right)$ and $\left(x_{1}^{2}, x_{2}^{2}\right)$, their utility values are $k_{1}^{1} x_{1}^{1}+k_{1}^{2} x_{2}^{1}$ and $k_{1}^{1} x_{1}^{2}+k_{1}^{2} x_{2}^{2}$. If $\left(x_{1}^{1}, x_{2}^{1}\right) \geq\left(x_{1}^{2}, x_{2}^{2}\right)$, we have $x_{1}^{1} \geq x_{1}^{2}$ and $x_{2}^{1} \geq x_{2}^{2}$; $u\left(x_{1}^{1}, x_{2}^{1}\right)=k_{1}^{1} x_{1}^{1}+k_{1}^{2} x_{2}^{1} \geq k_{1}^{1} x_{1}^{2}+k_{1}^{2} x_{2}^{2}=u\left(x_{1}^{2}, x_{2}^{2}\right)$. Increasing both the amounts of commodities at the same time will move the consumer to a more-preferred position, so the direction of increasing preference is the top right, as illustrated in Figure 2. If the amounts of commodities are increased, their positions can be shown by the shaded part in the coordinate system. The direction of increasing preference is indicated by the arrow. From the analysis, we know that $(x, \geq)$ and $(u(x), \geq)$ are posets; then, the utility function of perfect substitute is order-preserving.

4.2. Perfect Complements. Perfect complements are commodities that are always consumed together in fixed proportions. The two commodities complement each other. Suppose the fixed proportion is 1: $k_{2}$, i.e., $x_{1}: x_{2}=1: k_{2}$. If $x_{1}: x_{2}>1: k_{2}$, the first commodity is redundant, and the redundant amount does not do the consumer a bit of good. If $x_{1}: x_{2}<1: k_{2}$, another commodity is redundant, and the redundant amount is useless to the consumer. The utility function of perfect complements is

$$
u\left(x_{1}, x_{2}\right)=\min \left\{x_{1}, \frac{x_{2}}{k_{2}}\right\} .
$$

There are three function values $u_{2}^{1}, u_{2}^{2}$, and $u_{2}^{3}$, and $u_{2}^{1}<u_{2}^{2}<u_{2}^{3}$. Their indifference curves $\min \left\{x_{1}, x_{2} / k_{2}\right\}=u_{2}^{1}$, $\min \left\{x_{1}, x_{2} / k_{2}\right\}=u_{2}^{2}$, and $\min \left\{x_{1}, x_{2} / k_{2}\right\}=u_{2}^{3}$ are depicted in Figure 3 , respectively. The indifference curves are L-shaped, with the vertex of the $L$ occurring where the proportion of the two commodities is 1: $k_{2}$. Increasing both the commodities at the same time will move the consumer to a more-preferred position, so the direction of increasing preference is again the top right. 


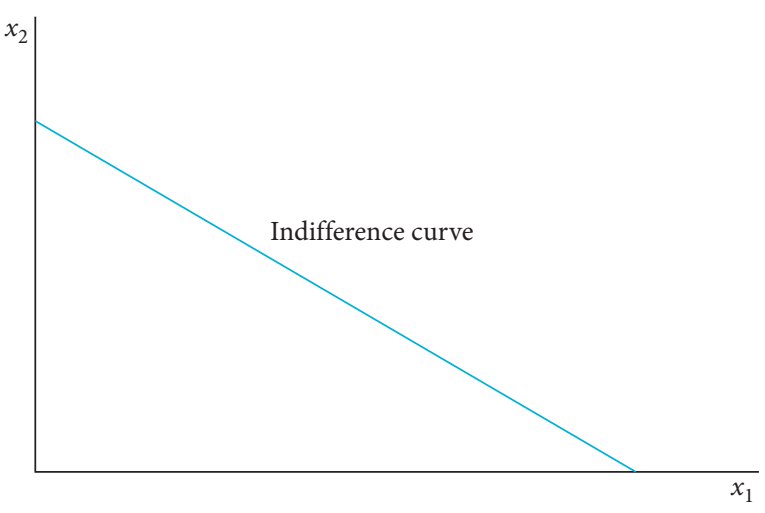

FIgURE 1: The indifference curve of perfect substitutes.

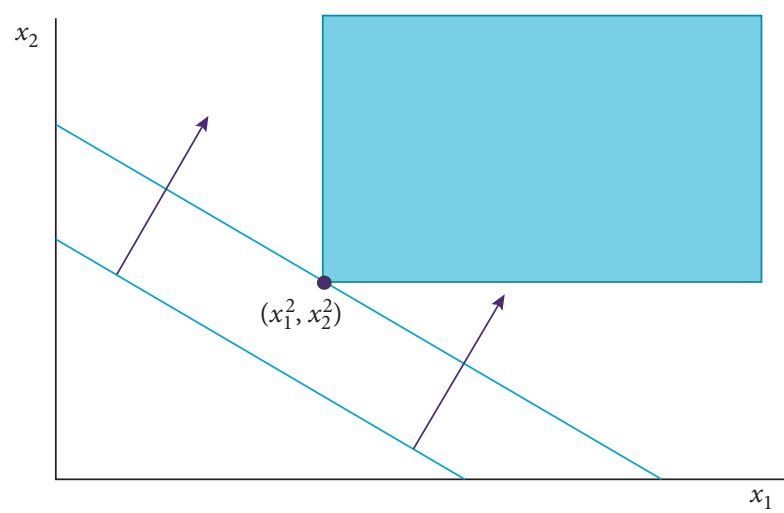

FIGURE 2: The preference and commodities for perfect substitutes.

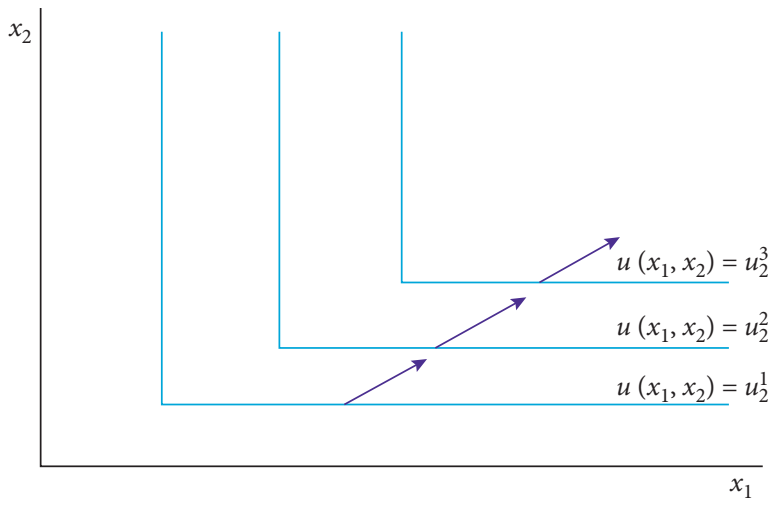

Figure 3: The indifference curve of perfect complements.

Utility function values of $\left(x_{1}^{1}, x_{2}^{1}\right)$ and $\left(x_{1}^{2}, x_{2}^{2}\right)$ are $\min \left\{x_{1}^{1}, x_{2}^{1} / k_{2}\right\}$ and $\min \left\{x_{1}^{2}, x_{2}^{2} / k_{2}\right\}$. If $\left(x_{1}^{1}, x_{2}^{1}\right) \geq\left(x_{1}^{2}, x_{2}^{2}\right)$, then $x_{1}^{1} \geq x_{1}^{2} \quad$ and $x_{2}^{1} / k_{2} \geq x_{2}^{2} / k_{2}$ and then $\min \left\{x_{1}^{1}, x_{2}^{1} / k_{2}\right\} \geq \min \left\{x_{1}^{2}, x_{2}^{2} / k_{2}\right\}$. If the amounts of commodities are increased, their positions are shown by the shaded part in Figure 4. $(x, \geq)$ and $(u(x), \geq)$ are posets; then, the utility function of perfect complements is order-preserving.

4.3. Bads. A bad is a commodity that the consumer does not like. If the two commodities are bads, the more the commodities, the lower the preference. With the increase

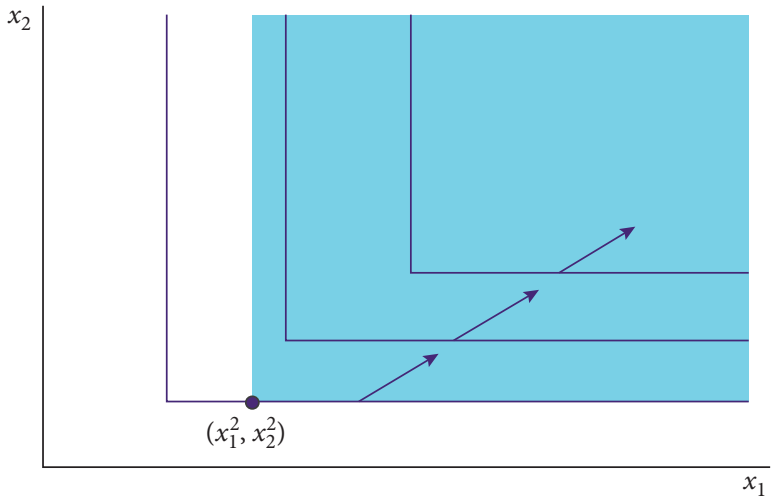

Figure 4: The preference and commodities for perfect complements.

of commodity quantity, the value of the utility function will be smaller and smaller. That is to say, if $\left(x_{1}^{1}, x_{2}^{1}\right) \geq\left(x_{1}^{2}, x_{2}^{2}\right), u\left(x_{1}^{1}, x_{2}^{1}\right) \leq u\left(x_{1}^{2}, x_{2}^{2}\right)$, then the utility function of bads is order-reversing. If the first commodity is a bad and another is not a bad, we usually put a negative sign before the bad item, or put the bad item in the denominator for the utility function of bads; then, the utility function of bads is neither order-preserving nor orderreversing. For example, the utility function is the following form:

$$
u\left(x_{1}, x_{2}\right)=-x_{1}+x_{2}
$$

Indifference curves are depicted in Figure 5; the direction of increasing preference is top left, toward the direction of decreasing the first commodity and increasing the second commodity, just as the arrows in the diagram illustrate. For any consumption bundles $\left(x_{1}^{1}, x_{2}^{1}\right)$ and $\left(x_{1}^{2}, x_{2}^{2}\right)$, their utility values are $u\left(x_{1}^{1}, x_{2}^{1}\right)=-x_{1}^{1}+x_{2}^{1}$ and $u\left(x_{1}^{2}, x_{2}^{2}\right)=-x_{1}^{2}+x_{2}^{2}$. If $\left(x_{1}^{1}, x_{2}^{1}\right) \geq\left(x_{1}^{2}, x_{2}^{2}\right)$, inequality $u\left(x_{1}^{1}, x_{2}^{1}\right) \geq u\left(x_{1}^{2}, x_{2}^{2}\right)$ may not be valid.

So, the utility function is neither order-preserving nor order-reversing.

4.4. Neutrals. A commodity is a neutral commodity if the consumer does not care about it. If the second commodity is a neutral, the consumer only cares about the first commodity, but does not care at all about the second commodity. The more the first commodity, the higher the consumer preference. The consumer preference will not change when increasing or decreasing amount of the second commodity. In this case, indifference curves will be vertical lines as depicted in Figure 6.

For any consumption bundles $\left(x_{1}^{1}, x_{2}^{1}\right)$ and $\left(x_{1}^{2}, x_{2}^{2}\right)$, if $x_{1}^{1} \geq x_{1}^{2}$ and $x_{2}^{1} \leq x_{2}^{2}$, the utility function values are $u\left(x_{1}^{1}, x_{2}^{1}\right), u\left(x_{1}^{2}, x_{2}^{2}\right)$, and $u\left(x_{1}^{1}, x_{2}^{1}\right) \geq u\left(x_{1}^{2}, x_{2}^{2}\right)$. So, the utility function of neutrals is neither order-preserving nor order-reversing. If the two commodities are neutrals, the consumer preference will not change when increasing or decreasing the commodities; the utility function of neutrals is neither order-preserving nor order-reversing. 


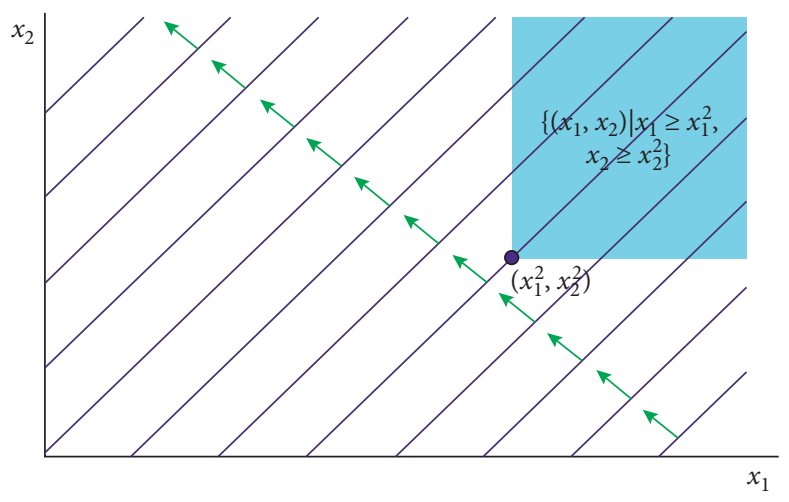

FIgURE 5: The preference and commodities for bads.

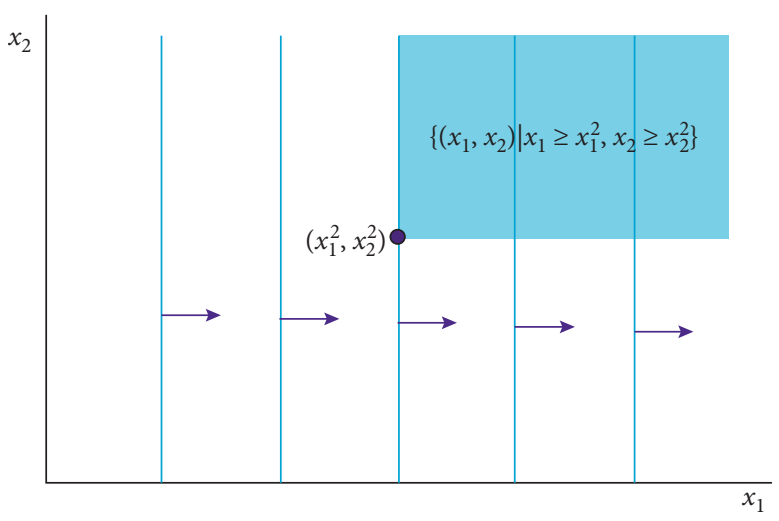

FIGURE 6: The preference and commodities for neutrals.

4.5. Satiation. We sometimes want to consider a situation involving satiation, where there is some overall best bundle for the consumer, and the "closer" consumer is to that best bundle, the better off the consumer is in terms of his own preferences.

Suppose the consumer has the most preferred bundle of commodities $\left(\bar{x}_{1}, \bar{x}_{2}\right)$, and the closer bundle to $\left(\bar{x}_{1}, \bar{x}_{2}\right)$, the greater the utility value, and $\left(\bar{x}_{1}, \bar{x}_{2}\right)$ is called a satiation point. As depicted in Figure 7, the direction of increasing preference is the satiation point.

There exists two consumption bundles $\left(x_{1}^{1}, x_{2}^{1}\right)$, $\left(x_{1}^{2}, x_{2}^{2}\right), \quad$ and $\quad x_{1}^{1}=\bar{x}_{1}-\varepsilon, \quad x_{2}^{1}=\bar{x}_{2}-\varepsilon, \quad x_{1}^{2}=\bar{x}_{1}+2 \varepsilon$, $x_{2}^{2}=\bar{x}_{2}+2 \varepsilon$, and $\varepsilon>0 . \quad x_{1}^{1}<x_{1}^{2} \quad$ and $\quad x_{2}^{1}<x_{2}^{2}$, i.e., $\left(x_{1}^{1}, x_{2}^{1}\right)<\left(x_{1}^{2}, x_{2}^{2}\right)$. Since consumption bundle $\left(x_{1}^{1}, x_{2}^{1}\right)$ is closer to satiation point than $\left(x_{1}^{2}, x_{2}^{2}\right)$ to satiation point, then utility function value of $\left(x_{1}^{1}, x_{2}^{1}\right)$ is greater than the utility function value of $\left(x_{1}^{2}, x_{2}^{2}\right)$. That is, $u\left(x_{1}^{1}, x_{2}^{1}\right)>u\left(x_{1}^{2}, x_{2}^{2}\right)$, as depicted in Figure 7. Indifference curves are closed curves; there exists a consumption bundle $\left(x_{1}^{3}, x_{2}^{3}\right)$ which is indifferent to consumption bundle $\left(x_{1}^{2}, x_{2}^{2}\right)$, but $\left(x_{1}^{3}, x_{2}^{3}\right) \leq\left(x_{1}^{1}, x_{2}^{1}\right)$. Thus, the utility function of satiation is neither order-preserving nor order-reversing.

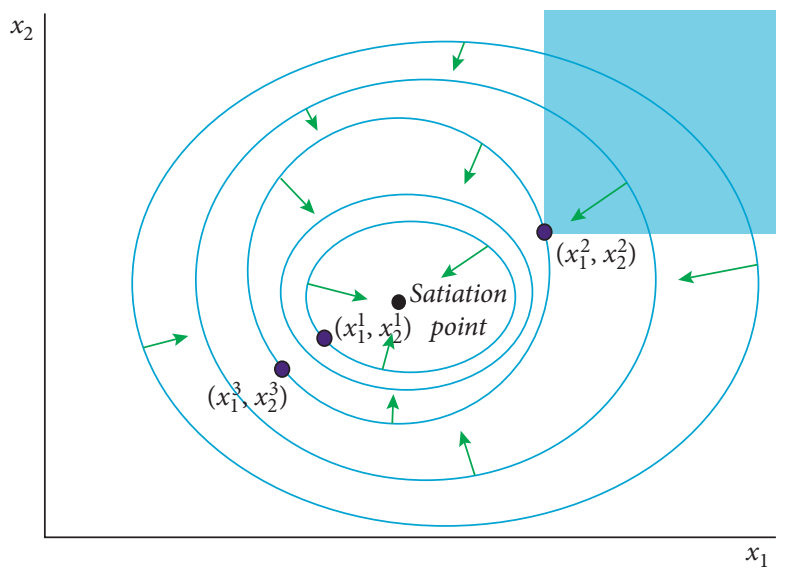

Figure 7: The preference and commodities for satiation.

\section{Conclusions}

Customer preference is an important market information during decision-making. Management and economics believe that income and price play decisive roles in consumer 
demand for commodities. However, there is no analysis of the relationship between consumer demand and utility when income and price are not constrained. Furthermore, customer utility is always determined by the amount of commodities in real life. Consumption bundles are reflexive, antisymmetric, and transitive; then, the bundle set with the binary relation $\leq$ is a poset. Utility values are complete, reflexive, antisymmetric, and transitive; then, the set of utility values with $\leq$ is a chain. The utility function is orderpreserving if the amount of commodities in the consumption bundle is greater, and the utility value also is greater. The utility function is order-reversing if the amount of commodities is smaller, but the utility value is greater. The analysis of order-preserving or order-reversing mapping is helpful to guide, improve, and optimize consumption behavior and provide the basis for the market strategies. Furthermore, if customer preference is affected by multiple attributes of commodity and the mapping relationships between different attributes and preference are inconsistent, the mapping relationship is a further research.

\section{Data Availability}

The data used to support the findings of this study are included within the article.

\section{Conflicts of Interest}

The author declares that there are no conflicts of interest.

\section{Acknowledgments}

This work was funded by the National Natural Science Foundation of China (Project no. 71901 031).

\section{References}

[1] F. Aleskerov, D. Bouyssou, and B. Monjardet, Utility Maximization, Choice and Preference, Springer, New York City, USA, 2007.

[2] K.-O. Kruse, "Kardinalität und die Aufspaltung von Höhenund Risikopräferenz beim Bernoulli-Prinzip," OperationsResearch-Spektrum, vol. 19, no. 1, pp. 31-34, 1997.

[3] B. Smeulders, Y. Crama, and F. C. R. Spieksma, "Revealed preference theory: an algorithmic outlook," European Journal of Operational Research, vol. 272, no. 3, pp. 803-815, 2019.

[4] W. Greiner and K. Klose, "Lebensqualitätsbewertung und Utilities in der Gesundheitsökonomie," Zeitschrift für Evidenz, Fortbildung und Qualität im Gesundheitswesen, vol. 108, no. 2-3, pp. 120-125, 2014.

[5] P. J. Neumann, S. J. Goldie, and M. C. Weinstein, "Preferencebased measures in economic evaluation in health care," Annual Review of Public Health, vol. 21, no. 1, pp. 587-611, 2000.

[6] D. A. Revicki and R. M. Kaplan, "Relationship between psychometric and utility-based approaches to the measurement of health-related quality of life," Quality of Life Research, vol. 2, no. 6, pp. 477-487, 1993.

[7] K. S. Boye, L. S. Matza, D. H. Feeny, J. A. Johnston, L. Bowman, and J. B. Jordan, "Challenges to time trade-off utility assessment methods: when should you consider alternative approaches?" Expert Review of Pharmacoeconomics \& Outcomes Research, vol. 14, no. 3, pp. 437-450, 2014.

[8] M. Bahrampour, J. Byrnes, R. Norman, P. A. Scuffham, and M. Downes, "Discrete choice experiments to generate utility values for multi-attribute utility instruments: a systematic review of methods," The European Journal of Health Economics, vol. 21, no. 7, pp. 983-992, 2020.

[9] S. Karray and S. H. Amin, "Cooperative advertising in a supply chain with retail competition," International Journal of Production Research, vol. 53, no. 1, pp. 88-105, 2015.

[10] V. I. Lau, F. Xie, J. Basmaji et al., "Health-related quality-oflife and cost utility analyses in critical care: a systematic review," Critical Care Medicine, vol. 49, no. 2021, pp. 575-588, 2021.

[11] Y. K. Li, N. Alolabi, M. N. Kaur, and A. Thoma, "A systematic review of utilities in hand surgery literature," The Journal of Hand Surgery, vol. 40, no. 5, pp. 997-1005, 2015.

[12] B. Liu, G. G. Cai, and A. A. Tsay, "Advertising in asymmetric competing supply chains," Production and Operations Management, vol. 23, no. 11, pp. 1845-1858, 2014.

[13] I. Simonson, "Determinants of customers' responses to customized offers: conceptual framework and research propositions," Journal of Marketing, vol. 69, no. 1, pp. 32-45, 2005.

[14] S. M. Szabo, I. F. Audhya, D. C. Malone, D. Feeny, and K. L. Gooch, "Characterizing health state utilities associated with Duchenne muscular dystrophy: a systematic review," Quality of Life Research, vol. 29, no. 3, pp. 593-605, 2020.

[15] S.-D. Wang, Y.-W. Zhou, J. Min, and Y.-G. Zhong, "Coordination of cooperative advertising models in a one-manufacturer two-retailer supply chain system," Computers \& Industrial Engineering, vol. 61, no. 4, pp. 1053-1071, 2011.

[16] G. Wei, X. Chen, and X. Qin, "Product greenness and pricing strategy of supply chain incorporating asymmetric heterogeneous preferences," IEEE Access, vol. 9, no. 2021, pp. 11563-11584, 2021.

[17] N. Zhao, Q. Wang, P. Cao, and J. Wu, "Pricing decisions with reference price effect and risk preference customers," International Transactions in Operational Research, vol. 28, no. 2021, pp. 2081-2109, 2021.

[18] N. Irtija, F. Sangoleye, and E. E. Tsiropoulou, "Contracttheoretic demand response management in smart grid systems," IEEE Access, vol. 8, pp. 184976-184987, 2020.

[19] P. Vamvakas, E. E. Tsiropoulou, S. Papavassiliou, and J. Baras, "Optimization and resource management in NOMA wireless networks supporting real and non-real time service bundling," in Proceedings of the IEEE Symposium on Computers and Communications (ISCC), IEEE, Heraklion, Greece, 3 July 2017.

[20] F. Zhang, L. Zhu, and G. Wang, "Study on PROMETHEE method optimization based on poset," Operations Research and Management Science, vol. 29, pp. 10-16, 2020.

[21] H. R. Varian, Intermediate Microeconomicspp. 1-72, Norton, New York, NY, US, 8th edition, 2010. 